\title{
PAPER
}

\section{Discontinuing antiepileptic drugs in patients who are seizure free on monotherapy}

\author{
L M Specchio, L Tramacere, A La Neve, E Beghi
}

J Neurol Neurosurg Psychiatry 2002;72:22-25

See end of article for authors' affiliations

.....................

Correspondence to: Professor L M Specchio, Centro per l'Epilessia,

Clinica Neurologica I, Università di Bari,

Dipartimento di Ścienze Neurologiche e

Psichiatriche, Ospedale

Policlinico, Piazza G

Cesare, 70124 - Bari,

Italy;

epilepsy@cimedoc.uniba.it

Received 14 September

2000

In revised form 12 March

2001

Accepted 10 May 2001

\begin{abstract}
Objectives: To assess the recurrence rate of epilepsy attributable to discontinuation of treatment in seizure free patients and to identify the risk factors for recurrence.

Methods: 330 patients referred to an epilepsy centre who were seizure free for at least 2 years while on stable monotherapy were the study population. Discontinuation of antiepileptic drugs (AEDs) was proposed to all eligible patients or to their carers after discussion of the risks and benefits. Depending on whether they accepted or refused treatment withdrawal, the patients were stratified into two cohorts and followed up until seizure relapse or 31 March 1999, whichever came first. For each patient, records were taken of the main demographic and clinical variables.

Results: The sample comprised 225 patients who entered the discontinuation programme and 105 who decided to continue treatment. Twenty nine patients $(28 \%)$ continuing treatment had a relapse, compared with $113(50 \%)$ of those entering the withdrawal programme. For patients continuing treatment, the probability of remission was $95 \%$ at 6 months, $91 \%$ at 12 months, $82 \%$ at 24 months, $80 \%$ at 36 months, and $68 \%$ at 60 months. The corresponding values for patients discontinuing treatment were $88 \%, 74 \%, 57 \%, 51 \%$, and $48 \%$. After adjusting for the principal prognostic factors, in patients discontinuing AEDs the risk of seizure relapse was 2.9 times that of patients continuing treatment. A relation was also found between relapse and duration of active disease, number of years of remission while on treatment, and abnormal psychiatric findings.

Conclusions: Seizure free referral patients on stable monotherapy who elect to withdraw drug treatment are at higher risk of seizure relapse compared with patients continuing treatment. Severity of disease and seizure free period are significant prognostic factors.
\end{abstract}

n patients with epilepsy who are seizure free for a period while on antiepileptic drugs (AEDs), the question arises whether treatment can be withdrawn. The decision to discontinue AEDs is based on the chance of remaining seizure free after drug withdrawal, the presence of factors predictive of a higher risk of seizure recurrence, and the medical and social consequences of the withdrawal compared with continuation of treatment. The risk of seizure relapse after withdrawal of AEDs has been estimated at from $10 \%$ to $70 \%$ depending on the method and design of the studies. Based on a meta-analysis of the literature, ${ }^{1}$ the risk of relapse after drug withdrawal was $25 \%$ at 1 year and $29 \%$ at 2 years. Several factors have been implicated in the risk of relapse, including age at onset of seizures, ${ }^{2-7}$ age at treatment withdrawal, ${ }^{5-11}$ family history of epilepsy, ${ }^{52-14}$ recognised aetiology of epilepsy or abnormal neurological or psychiatric findings, ${ }^{5} 89^{13-18}$ EEG abnormalities, ${ }^{7} 0^{14-16}$ 18-22 number of seizures preceding remission, ${ }^{28} 9111315-172324$ and duration of seizure free period on treatment. ${ }^{11} 121625$

The risk of seizure relapse attributable to drug discontinuation is less well defined. The only study comparing continued antiepileptic treatment and drug withdrawal showed that $78 \%$ of patients continuing and 59\% of those stopping AEDs remained seizure free two years after randomisation. ${ }^{11}$ In that study the patients were enrolled regardless of whether they were taking one or more drugs. The authors found that taking more than one AED significantly increased the risk of relapse. $^{20}$

The aim of the present study was to compare treatment continuation and slow withdrawal in patients on monotherapy, evaluating the risk of seizure relapse and the factors influencing that risk.

\section{PATIENTS AND METHODS}

Patients with epilepsy referred to the Epilepsy Centre of the University of Bari, Italy, were the target population. To be eligible for the study, each patient had (1) to have epilepsy, defined as two or more unprovoked seizures occurring at least 24 hours apart, ${ }^{26}(2)$ to have been seizure free for at least 2 consecutive years, and (3) to have been on monotherapy for at least 1 year. Seizure free patients receiving two or more AEDs were encouraged to withdraw the drug considered least effective and to continue on monotherapy for 12 months or longer before being reconsidered.

At a standard follow up visit, the discontinuation of AEDs was proposed to all eligible patients, or to their carers when indicated, after discussion of the risks and benefits. Depending on whether they accepted or refused treatment withdrawal, and with their informed consent, the patients were then stratified into two cohorts and followed up until seizure relapse or 31 March 1999, whichever came first.

For each patient, records were taken of the main demographic and clinical variables, including family history of febrile seizures or epilepsy (first degree relatives), history of febrile convulsions, age at onset of seizures, seizure type(s) ${ }^{27}$ and number, epilepsy syndrome ${ }^{28}$ duration of active disease (dates of first and last seizure) including seizure relapse after starting treatment, neurological and psychiatric findings (based on the treating physician's judgment and coded as normal or abnormal), aetiology (based on clinical or laboratory findings, as required by the treating physician, and coded with reference to the type of underlying condition),

Abbreviations: AEDs, antiepileptic drugs 
EEG features at study entry (based on the local neurophysiologist's report and coded as normal, slow, or epileptiform), Features of CT/MRI (based on the local neuroradiologist's report and coded as normal or abnormal), number of drugs used, and duration of the seizure free period. These variables were assessed as prognostic factors. As most of the patients recruited in the study had been followed by three of us (LMS, LT, ALN) since the date of diagnosis, each prognostic factor could be accurately defined and a large proportion of patients could be classified in specific syndromic categories.

In patients discontinuing treatment, AEDs were tapered using a standard procedure: $25 \%$ of the maintenance dose at entry into the study was subtracted every 3 months or longer, depending on factors such as daily dose or patient's request. After withdrawal of treatment, follow up visits were scheduled every 3 months during the lst year, every 6 months during the 2nd year, and annually thereafter. Patients continuing treatment were seen at 3 month or 6 month intervals. When reported by the patient or carer, seizure relapse was recorded and dated.

Data were processed using the SPSS statistical package. The background characteristics of the two cohorts were compared using the $\chi^{2}$ test for heterogeneity.

The intervals from study entry (the date patients elected to continue or discontinue treatment) and the date of seizure relapse (or the date of last follow up in subjects remaining seizure free) were calculated to the nearest month and summarised using actuarial life tables. The overall probability of remaining seizure free in the two cohorts was analyzed using the Kaplan-Meier survival analysis. ${ }^{29}$

The significance of each prognostic factor was assessed by the log rank test in single variable analysis. ${ }^{30}$ Multivariate analysis was then performed using the Cox proportional hazard model, ${ }^{31}$ including the factors found to be significantly associated with the risk of relapse and those thought to be clinically relevant. The model also included the interaction terms.

\section{RESULTS}

Between August 1982 and October 1998, a total of 330 consecutive patients were enrolled. Of these, 177 became eligible after treatment was simplified, as they had been taking two or more drugs. A total of 225 patients entered the discontinuation programme and 105 decided to continue treatment. The demographic and clinical characteristics of the two cohorts are set out in table 1. Patients discontinuing AEDs were younger, and had a poorer education, a shorter disease duration or a normal EEG at entry, less frequent seizure relapse after starting treatment, a shorter duration of active disease, and more years of remission. The mean (SD) follow up in the two cohorts was 48.0 (49.4) and 46.6 (37.6) months. Eighty nine per cent of patients were followed up for more than 6 months, $75 \%$ for more than 12 months, $54 \%$ for more than 24 months, 38\% for more than 48 months, and 25\% for more than 72 months. There were only five drop outs among patients discontinuing and four among those continuing treatment. Twenty nine patients $(28 \%)$ continuing treatment had a relapse, compared with $113(50 \%)$ of those in the withdrawal programme. In this group, 46 relapsed after completing drug withdrawal and 67 relapsed during the tapering.

The cumulative time dependent probability of remaining seizure free was significantly different in the two cohorts (fig 1). In patients continuing treatment, the probability of remission was $95 \%$ at 6 months, $91 \%$ at 12 months, $82 \%$ at 24 months, $80 \%$ at 36 months, and $68 \%$ at 60 months. The corresponding values for patients discontinuing treatment were 88 , $74,57,51$, and $48 \%$.

After adjusting for the principal prognostic factors, in patients who discontinued AEDs the risk of seizure relapse was 2.9 times that of patients continuing treatment (table 2).
Table 1 Demographic and clinical characteristics of patients discontinuing or continuing antiepileptic drugs

\begin{tabular}{|c|c|c|c|c|c|}
\hline \multirow[b]{2}{*}{ Variable } & \multicolumn{2}{|c|}{$\begin{array}{l}\text { Treatment } \\
\text { withdrawn }\end{array}$} & \multicolumn{2}{|c|}{$\begin{array}{l}\text { Treatment } \\
\text { continued }\end{array}$} & \multirow[b]{2}{*}{ pValue } \\
\hline & $n$ & $\%$ & $\mathrm{n}$ & $\%$ & \\
\hline Total & 225 & 100 & 105 & 100 & \\
\hline \multicolumn{6}{|l|}{ Age $(y):$} \\
\hline$<15$ & 38 & 17 & 4 & 4 & $<0.001$ \\
\hline $15-34$ & 158 & 70 & 77 & 73 & \\
\hline $35-54$ & 22 & 10 & 18 & 17 & \\
\hline$>54$ & 7 & 3 & 6 & 6 & \\
\hline \multicolumn{6}{|l|}{ Sex: } \\
\hline Men & 103 & 46 & 42 & 40 & NS \\
\hline \multirow{2}{*}{\multicolumn{6}{|c|}{ Education*: }} \\
\hline & & & & & \\
\hline None & 4 & 2 & 1 & 1 & 0.028 \\
\hline Basic & 158 & 70 & 60 & 57 & \\
\hline High school & 56 & 25 & 42 & 40 & \\
\hline University & 6 & 3 & 2 & 2 & \\
\hline Occupation*: & & & & & \\
\hline None & 23 & 10 & 8 & 8 & NS \\
\hline Student & 56 & 25 & 16 & 15 & \\
\hline Housewife & 53 & 24 & 29 & 28 & \\
\hline Skilled/unskilled worker & 85 & 38 & 44 & 42 & \\
\hline Retired & 3 & 1 & 2 & 2 & \\
\hline Disability pensioner & 4 & 2 & 6 & 6 & \\
\hline Age at first seizure $(y)$ : & & & & & \\
\hline$<15$ & 137 & 61 & 58 & 55 & NS \\
\hline $15-34$ & 73 & 33 & 40 & 38 & \\
\hline $35-54$ & 11 & 5 & 4 & 4 & \\
\hline$>54$ & 2 & 1 & 2 & 3 & \\
\hline Disease duration at entry $(y)$ : & & & & & \\
\hline 2 & 5 & 2 & - & - & $<0.001$ \\
\hline $3-5$ & 65 & 29 & 18 & 17 & \\
\hline $6-10$ & 78 & 35 & 27 & 26 & \\
\hline$>10$ & 76 & 34 & 60 & 57 & \\
\hline Family history of epilepsy: & & & & & \\
\hline No & 181 & 80 & 90 & 86 & NS \\
\hline Yes & 44 & 20 & 15 & 14 & \\
\hline History of febrile seizures: & & & & & \\
\hline No & 206 & 92 & 89 & 85 & NS \\
\hline Yes & 19 & 8 & 16 & 15 & \\
\hline Epilepsy syndrome: & & & & & \\
\hline Partial idiopathic & 8 & 4 & 1 & 1 & NS \\
\hline Symptomatic & 23 & 10 & 15 & 14 & \\
\hline Cryptogenic & 118 & 52 & 55 & 52 & \\
\hline Generalised idiopathic & 73 & 33 & 33 & 32 & \\
\hline Symptomatic/cryptogenic & 3 & 1 & 1 & 1 & \\
\hline Abnormal neurological examin & ation & & & & \\
\hline No & 212 & 94 & 96 & 91 & NS \\
\hline Yes & 13 & 6 & 9 & 9 & \\
\hline Abnormal psychiatric examinat & & & & & \\
\hline No & 207 & 92 & 95 & 90 & NS \\
\hline Yes & 18 & 8 & 10 & 10 & \\
\hline EEG at study entry* & & & & & \\
\hline Normal & 63 & 29 & 18 & 18 & 0.023 \\
\hline Abnormal, non-epileptiform & 112 & 53 & 49 & 48 & \\
\hline Epileptiform & 38 & 18 & 35 & 34 & \\
\hline Recognised aetiology & & & & & \\
\hline No & 198 & 88 & 89 & 85 & NS \\
\hline Yes & 27 & 12 & 16 & 15 & \\
\hline Abnormal CT/MRI & & & & & \\
\hline No & 171 & 87 & 81 & 83 & NS \\
\hline Yes & 25 & 13 & 17 & 17 & \\
\hline Seizure relapse after start of tre & atment & & & & \\
\hline No & 66 & 29 & 18 & 17 & 0.018 \\
\hline Yes & 159 & 71 & 87 & 83 & \\
\hline No of drugs used after onset of & seizure & & & & \\
\hline 1 & 113 & 50 & 40 & 38 & NS \\
\hline 2 & 65 & 29 & 43 & 41 & \\
\hline $3+$ & 47 & 21 & 22 & 21 & \\
\hline Duration of active disease (y) & & & & & \\
\hline 2 & 12 & 5 & 7 & 7 & 0.012 \\
\hline $3-5$ & 87 & 39 & 27 & 26 & \\
\hline $6-10$ & 65 & 29 & 24 & 23 & \\
\hline$>10$ & 59 & 27 & 46 & 44 & \\
\hline No of years of remission at stuc & dy entry & & & & \\
\hline 2 & 31 & 14 & 31 & 30 & $<0.001$ \\
\hline $3-5$ & 148 & 67 & 62 & 60 & \\
\hline $6-10$ & 26 & 12 & 11 & 10 & \\
\hline$>10$ & 15 & 7 & - & - & \\
\hline
\end{tabular}




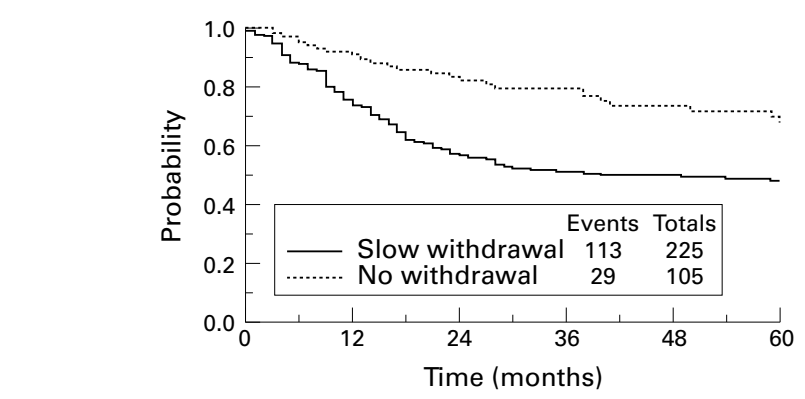

Patients at risk (events)

Slow withdrawal 225 (53) 164 (38) 114 (12) $95 \quad$ (2) $83 \quad$ (3) 70

$\begin{array}{llllllllllll}\text { No withdrawal } & 105 & \text { (8) } & 89 & \text { (8) } & 68 & \text { (3) } & 54 & \text { (4) } & 41 & \text { (2) } & 34\end{array}$

Figure 1 Actuarial percentage of seizure free patients stopping treatment or continuing treatment.

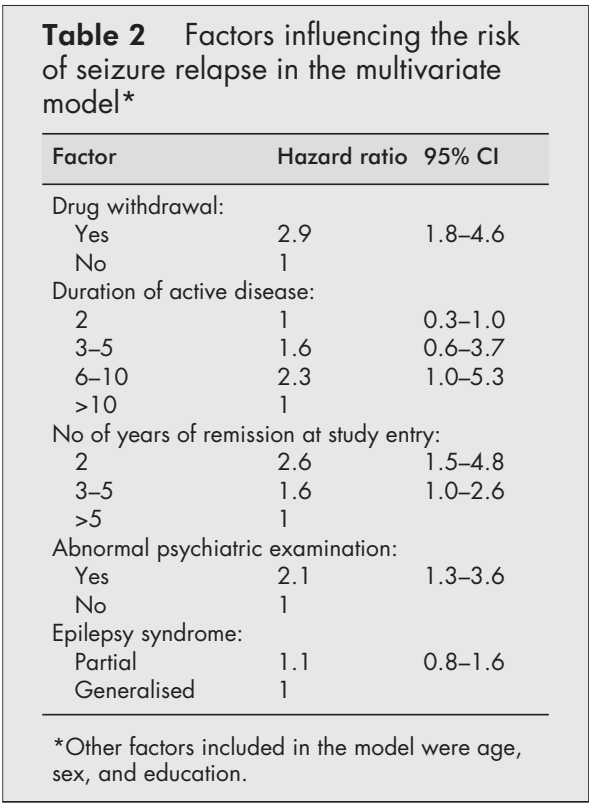

Besides drug treatment, several factors affected the risk of relapse. A correlation was found between relapse and duration of active disease and number of years of remission while on treatment. In addition, relapse was influenced by abnormal psychiatric findings. The risk of relapse also varied markedly according to the epilepsy syndrome. In patients with idiopathic partial epilepsies the 24 month risk of relapse was $0 \%$; the corresponding values for symptomatic partial epilepsies, cryptogenic partial epilepsies, idiopathic generalised epilepsies, and symptomatic or cryptogenic generalised epilepsies were $43,36,33$, and 50\%. However, compared with generalised epilepsies, there was only a 1.1 risk of relapse in partial epilepsies (table 2).

\section{DISCUSSION}

In this study patients who elected to withdraw from drug treatment had a significantly higher risk of recurrence of seizures. This finding is remarkable considering that in patients continuing treatment the duration of active disease was longer, there were more cases relapsing after starting treatment, and there were fewer years in remission. As this was not a randomised study, the difference in seizure recurrence might have been even greater if the two cohorts had been better balanced. However, the similarity between our data and those of the MRC Antiepileptic Drug Withdrawal Study Group ${ }^{11}$ was surprising. In that study, the 2 year risk of relapse was $22 \%$ in patients continuing and $41 \%$ in those withdrawing treatment. The present study found $18 \%$ and $43 \%$. Although the possibility of this being a chance finding cannot be excluded, it can also be argued that the differences in the clinical features of our two cohorts are not of such a magnitude as to confound the effects of treatment. The results of our multivariate analysis are in keeping with this assumption.

Compared with the pooled analysis of the literature, ${ }^{1}$ our untreated population had a higher risk of relapse. This contrasts with the fact that our sample was on monotherapy at entry, which may indicate less severe disease. Where examined, ${ }^{11}$ the recurrence rate seems higher in patients receiving polytherapy when starting to discontinue AEDs. In addition, most reports refer to children and, compared with childhood onset epilepsy, the risk of relapse in adolescent and adult onset epilepsy was greater. ${ }^{1}$

In accordance with the MRC study, the difference in the cumulative probabilities of relapse in the two groups tended to rise steeply during the lst year after stopping treatment and decreased after the 3rd year of follow up. This may be explained by decreasing compliance in patients continuing treatment and by the short period considered critical for relapse in patients stopping AEDs (less than 2 years). As shown by the continued follow up of the patients enrolled in the MRC trial, discontinuation of treatment did not affect the long term chance of seizure relapse..$^{32}$

In keeping with other reports, ${ }^{2} 58913-182325$ abnormal psychiatric findings, a longer duration of active disease, and a shorter duration of the seizure free period on treatment all increased the risk of seizure relapse.

In our study, older age at onset of seizures, family history of epilepsy and abnormal EEG findings did not predict greater susceptibility to seizure recurrence, although there are reports of a better outcome in patients with seizures starting after the age of $30 .{ }^{6}$ In the MRC study ${ }^{11}$ the age at first seizure was not influential. The non-significant role of the family history of epilepsy may be related to the difficulty of assessing this, as it may be heavily influenced by recall bias. Although the types of EEG features predicting relapse tend to differ across studies, ${ }^{1}$ the unremarkable role of the EEG can be explained here by the use of broad diagnostic criteria.

The risk tended to vary with the epilepsy syndrome, although not to a significant extent. This may be explained by the small numbers in some syndromic categories (idiopathic partial epilepsies, symptomatic or cryptogenic generalised epilepsies). Where reported, the syndromic classification of the epilepsies was a significant predictor of the outcome of epilepsy $^{33}$ and of the risk of seizure relapse after discontinuing treatment. ${ }^{6}$ This may explain some of the discrepancies across studies and reflects the concept that the effects of treatment withdrawal cannot be assessed without reference to case classification in the appropriate syndrome categories.

This study has several limitations. Firstly, patients were assigned to one of the two treatment arms on the basis of the their willingness to withdraw or continue drug treatment. However, in view of the similarity of our findings and those of the MRC study, ${ }^{11}$ selection bias should not have affected the results to any significant extent. Secondly, only patients who were on monotherapy were accepted. Thus, our series may include less severe cases than other studies in a similar setting, as those failing while switching from polytherapy would have been excluded before being considered eligible for entry. However, the purpose of this study was to assess the seizure outcome in patients continuing or stopping monotherapy. In addition, the selection of cases in stable monotherapy for at least 1 year contributed to a better definition of our inception cohort. Thirdly, this was not a population based study. Our patients probably presented more severe varieties of epilepsy, so the results are not applicable in any context other than a referral centre. Remission rates after drug withdrawal would presumably have been even higher in a more representative sample population. 


\section{ACKNOWLEDGEMENTS}

We thank Dr Saverio Staffieri and Dr Irene Floriani for statistical advice, Ms Judy Baggott for editorial assistance, and Miss Susanna Franceschi for typing the manuscript.

\section{Authors' affiliations}

L M Specchio, L Tramacere, A La Neve, Centro per l'Epilessia, Clinica Neurologica I, Università di Bari, Dipartimento di Scienze Neurologiche e Psichiatriche, Ospedale Policlinico, Piazza G Cesare, 70124 - Bari, Italy; epilepsy@cimedoc.uniba.it

E Beghi, Centro per l'Epilessia, Clinica Neurologica, Ospedale "San Gerardo", Monza; Istituto "Mario Negri", Milano, Italy

\section{REFERENCES}

1 Berg AT, Shinnar S. Relapse following discontinuation of antiepileptic drugs: a meta-analysis. Neurology 1994;44:601-8.

2 Juul-Jensen $\mathbf{P}$. Frequency of recurrence after discontinuation therapy in patients with epileptic seizures. Epilepsia 1964;5:352-63.

3 Janz D. In tema di remissione e di ricomparsa di crisi durante e dopo il trattamento farmacologico dell'epilessia. Bollettimo Lega Italiana contro I'Epilessa 1982;39:95-100.

4 Bouma PAD, Peters ACB, Arts RJHM, et al. Discontinuation of antiepileptic therapy: a prospective study in children. J Neurol Neurosurg Psychiatry 1987;50:1579-83.

5 Shinnar S, Berg AT, Moshé SL, et al. Discontinuing antiepileptic drugs in children with epilepsy: a prospective study. Ann Neurol 1994;35:534-45.

6 Avoni P, Riva R, Tinuper P, et al. Prognosis of epilepsies in antiepileptic drug discontinuation. Epilepsia 1996;37(suppl 4):58-9.

7 Braathen G. Melander H. Early discontinuation of treatment in children with uncomplicated epilepsy: a prospective study with a model for prediction of outcome. Epilepsia 1997;38:561-9.

8 Holowach J, Thurston DL, O'Leary J. Prognosis in childhood epilepsy. Follow up study of 148 cases in which therapy had been suspended after prolonged anticonvulsant control. N Engl J Med 1972;286:69-74.

9 Holowach Thurston J, Thurston DL, et al. Prognosis in childhood epilepsy. Additional follow up of 148 children 15 to 23 years after withdrawal of anticonvulsant therapy. N Engl J Med 1982;306:831-6.

10 Shinnar S, Vining EPG, Mellits ED, et al. Discontinuing antiepileptic medication in children with epilepsy after 2 years without seizures. $N$ Engl J Med 1985;313:976-80.

11 Medical Research Council Antiepileptic Drug Withdrawal Study Group. Randomised study of antiepileptic drug withdrawal in patients in remission. Lancet 1991;337:1175-80.

12 Oller-Daurella L, Marquez J. Survey of 100 epileptics who have not had seizures for 10 years or more. Epilepsia 1972;13:161-70.

13 Arts WFM, Visser LH, Loonen MCB, et al. Follow-up of 146 children with epilepsy after withdrawal of antiepileptic therapy. Epilepsia 1988;29:244-50.

14 Dooley J, Gordon K, Camfield P, et al. Discontinuation of anticonvulsant therapy in children free of seizures for 1 year: A prospective study. Neurology 1996;46:969-74.
15 Emerson R, D'Souza BJ, Vining EP, et al. Stopping medication in children with epilepsy. Predictors of outcome. N Engl J Med 1981;304:1125-9.

16 Todt $\mathbf{H}$. The late prognosis of epilepsy in childhood: results of a prospective follow-up study. Epilepsia 1984;25:137-44.

17 Oller-Daurella L, Oller FV. Suppression of antiepileptic treatment. Eur Neurol 1987;27:106-13.

18 Tennison M Greenwood R, Lewis D, et al. Discontinuing antiepileptic drugs in children with epilepsy. A comparison of a six-week and a nine-month taper period. N Engl J Med 1994;330:1407-10.

19 Callaghan N, Garrett A, Goggin T. Withdrawal of anticonvulsant drugs in patients free of seizures for 2 years. N Engl J Med 1988;318:942-6.

20 Medical Research Council Antiepileptic Drug Withdrawal Study Group. Prognostic index for recurrence of seizures after remission of epilepsy. BM 1993;306:1374-8.

21 Tinuper $\mathbf{P}$, Avoni $\mathrm{P}$, Riva R, et al. The prognostic value of the electroencephalogram in antiepileptic drug withdrawal in partial epilepsies. Neurology 1996;47:76-8.

22 Andersson T, Braathn G, Persson A, et al. A comparison between 1 and 3 years of treatment in uncomplicated childhood epilepsy: a prospective study. II. The EEG as predictor of outcome after withdrawal of treatment. Epilepsia 1997;38:225-32.

23 Matricardi $M$, Brinciotti $M$, Benedetti P. Outcome after discontinuation of antiepileptic therapy in children with epilepsy. Epilepsia 1989;30:582-9.

24 Oller-Daurella L, Oller FVL. Influence of the "lost time" on the outcome of epilepsy. Eur Neurol 1991;31:175-7.

25 Nalin A, Galli V, Ferrari P, et al. Sospensione della terapia antiepilettica in soggetti con epilessia insorta nell'età infantile. Pediatr Med Chir 1982;4:601-6.

26 Commission on Epidemiology and Prognosis of the International League Against Epilepsy. Guidelines for epidemiologic studies on epilepsy. Epilepsia 1993;34:592-6.

27 Commission on Classification and Terminology of the International League Against Epilepsy. Proposal for revised clinical and electroencephalographic classification of epileptic seizures. Epilepsia 1981;22:489-501

28 Commission on Classification and Terminology of the International League Against Epilepsy. Proposal for revised classification of epilepsies and epileptic syndromes. Epilepsia 1989;30:389-98.

29 Kaplan EL, Meier P. Non-parametric estimation for incomplete observations. Journal of the American Statististical Association 1958;53:457-81.

30 Peto R, Pike MC, Armitage P, et al. Design and analysis of randomized clinical trials requiring prolonged observation of each patient. $\mathrm{Br} J$ Cancer 1977;35:1-39.

31 Cox DR. Regression models and life tables. JR Stat Soc B 1972;34:187-220.

32 Chadwick D, Taylor J, Johnson T, et al. Outcomes after seizure recurrence in people with well-controlled epilepsy and the factors that influence it. Epilepsia 1996;37:1043-50.

33 Sander JWAS. Some aspects in the prognosis of the epilepsies. Epilepsia 1993;34:1007-16. 